\title{
AARD, FUNKSIE EN INVLOED VAN DIE LITERATUUR
}

Binne die raamwerk van die tema van hierdie simposium gaan dit om twee komponente:

- die literatuur, meer bepaald die letterkundige werk of woordkunswerk met sy drie genres en

- die gemeenskap, die ontvangers of belewers vall die literatuur of doodgewoon die lescrs.

\section{Die aard van die literatuur}

I.I By die onderwerp word nie lank stilgestaan nie. Daar is 'n oneindige reeks definisies wat die kennerke van die literatuur omskryf en daar is bocke sonder tal oor hierdie onderwerp gepubliseer. Duisende bladsye sal seker nog daaraan gewy word. Opvattings oor die wese en aard van die literatuur verskil van dekade tot dekade en van eeu tot eeu en dit sy verre van my om nou iets nuuts daaraan toe te voeg. Die menings van enkele vooraanstaande literatore oor die aard van die literatuur kan soos volg saamgevat word:

1.1.1 Die medium van die letterkundige werk is die geskrewe of mondelinge taal. As 'n mens aan die Middelnederlandse letterkunde dink, dan weet ons dat dié letterkunde nie by die beroemde versreël van 'n verlangende monnik: Hebban olla vogela nestas hagunnan hinase hic ende thu begin het nie. Dic rcël kan as 'n begin van die geskrewe Nederlandse letterkunde beskou word. Daar is egter heelwat aanduidings dat daar 'n letterkunde voor daardie reël bestaan het, hoewel die vervoermiddel van daardie letterkunde hoofsaaklik die mondelinge taal was.

1.1.2 Die essensie van die literêre werk is sy bepaalde vormlike eienskappe en sy fiktiewe en onverifieerbare aard. Dit hou onder andere in dat die wêreld of dic werklikheid van by voorbeeld die roman onderskeibaar, maar nie skeibaar van die werklikheid buite die roman is nie. Bennison Gray definieer die literêre werk as 'n onverifieerbare "moment-by-moment statement of an event" (1975:142). Ook F.C. Maatje (1976:20) beklemtoon die essensieel-fiktiewe aard van die literêre werk en die onverifieerba arheid van die literêre gegewe.

1.1.3 Die literêre werk het ongetwyfeld 'n uitwerking op die leser/belewer: Dit kan ontroerend en esteties-strelend wees of die teenoorgestelde 
uitwerking hê: beroerend en ontwrigtend. Herman Gorter se Mei is estetiesstrelend en bekoorlik-ontroerend. Niemand sal dit ontken nie. Plaas langs $M e i$ Leroux se Magersfontein, o Magersfontein, dan is die effek beroerend onder die vaandel van die estetiese kommunikasie wat eie is aan die literêre werk.

2.1.4 Ten slotte: Die literatuur, by name dus die letterkundige werk, is alomvattend. Saul Bellow, wenner van die Nobelprys vir letterkunde, het by die geleentheid van die oorhandiging van die prys gesê dat die literêre werk in sy onderskeiding van feitelike mededelings en wetenskaplike bevindings op skrif, alomvattend is en alle gebiede van die menslike bestaan dek. "How poor are they all" het hy hom geringskattend oor die nie-literêre uitgelaat. Hier het hy onder andere verwys na die veelfasettigheid of dic veelogigheid, ook wel genoem die multivalensie van die literêre werk.

Wanneer dus oor die literêre werk gepraat word, word dit wat byvoorbeeld in Nederland bekend staan as die sogenaamde "keukenmeidenliteratuur" buite rekening gelaat. Dit beteken nie dat 'n mens nie 'n geldige ondersoek na dergelike literatuur en sy wisselwerking met die gemeenskap kan instel nie. Inteendeel, ek kan byvoorbeeld verwys na die ondersoek wat 'n werkgroep onder leiding van Jos Gielen (1974) na die soort massaliteratuur ingestel het.

\section{Die wisselwerking tussen literatuur en gemeenskap}

2.1 Soos reeds hierbo gestel, gaan dit by die omskrywing van die gemeenskap om die ontvangers of die belewers van die literatuur. Gemeenskap imipliseer natuurlik 'n wyd geskakeerde groep lesers: die intellektuele, kultuurgerigte leser en die gewone leser. Die belewing van 'n bepaalde literêre werk hang dikwels saam met 'n leser se maatskaplike gebondenheid, selfs ook sy historiese gebondenheid (Gielen: 100).

Die waarde wat deur die eeue aan literêre werke geheg is, varieer: Wat vir een era aanvaarbaar was, is vir die volgende een minder goed. In die tydperk voor die opkoms van die Nederlandse Tagtigerkuns was die letterkunde - of dit wat deurgegaan het vir letterkunde - gemeengoed. Willem Kloos en sy medestanders het as kunstenaars ' $n$ ander instelling gehad en die visier van hulle kuns skerp gerig op 'n groepie geesgenote en so die literère kuns eksklusiewer gemaak. Hierop word later teruggekom.

\subsection{Onsterflikheid van die literère werk}

Die variasie in die opvattings van die gemeenskap cor die literatuur in samehang met die wyd geskakcerde opvattings van skeppende kunstenaars deur die eeue bring mee dat die oes aan onsternike litcrête werke eintlik skraal is. Onsterllik word natuurlik hier as 'n ideèle term gebruik. Die veranderde waardestelsels waaraan literêre werke deur die eeue onderhewig was, hou teoreties gesproke in dat werke uit dic verre verlede dalk nog onsterllikheid kan bereik as gevolg van veranderende opvattings en beskouings oor die wese en die aard van die literatuur. 
Om onsterflik te wees, moet 'n literêre werk voortreflike eienskappe hê. Dit bchoort onuitputlik te wees vir alle tye en gemcenskappe en dit moet die toets van elke stel norme vir die literêre werk deur die eeue kan deurstaan. Die "maker" van die onsterllike werk, aldus Schopenhauer, moet 'n mens wees met visie wie se werk ongeskonde deur alle eeue en gemeenskappe kan beweeg.

Die poësie van N.P. van Wyk Louw het die allure van onsterflikheid en sal ook moontlk onsterllk word. As 'n mens aan die ander kant na ons Afrikaanse prosa kyk, is die prentjie anders. Is dáár nie dalk die beperking van 'n te groot gebondenheid aan die konteks van ons tyd en gemeenskap nie? $\Lambda$ s die spanninge van ons tyd, veral ons eie gemeenskapsprobleme, eendag verbygaan - en mag God gee dat dit gebeur - wat gaan dan word van ons Magersfonteine en Poppie Nongenas? Sou hulle nie dalk gereduseer word tot slegs bakens in die literatuurgeskiedenis nie?

\subsection{Die outonomie van die literêre werk}

Bogenoemde het konsekwensies vir die outonomie van die literêre werk met die kunstenaar in sy spreekwoordelike ivoortoring. Iemand het onlangs gesê dat die bestaan van die ivoortoring op sigself al 'n contradictio in terminus is: Die einste ivoortoring kan mos nie tot stand kom sonder'n jagtog nie en in die besondere geval 'n jagtog op olifante. Iemand wat so ' $n$ jagtog op sy eentjie aanpak, is waansinnig en 'n mens kan aanneem dat 'n gemeenskap in die kleine ('n jaggeselskap) die "boustene" vir die ivoortoring bymekaar gemaak het.

Jauss, die groot formuleerder van die resepsie-estetika (Segers: 10) neutraliseer ook die outonomiegedagte van die literatuur en die literêre werk met sy opvatting van die literatuurgeskiedenis as 'n proses van produksie en resepsie.

\section{Funksie en invloed}

3.1 Die terme funksie en invloed met betrekking tot die literatuur sluit nou bymckaar aan en skuif wat betekenis betref, in sommige gevalle oor mekaar. Hulle word in die res van my betoog in hul samehang gebruik, hoewel die klem uiteindelik op ' $n$ bespreking van die funksie gaan val. Funksie is nie noodwendig of glad nie in die literêre werk ingebou nie. Tog kan 'n bepaalde soort leser'n bepaalde funksie definieer en ' $n$ bepaalde werk vir sekere doeleindes benut. Ek kom later hierop terug.

3.2 Die objek van die invloed van die literêre werk hoef nie altyd die gemeenskap te wees nie. Die invloed van die literêre werk kan ook ander literêre werke geld. Dit is ongetwyfeld so - om naby die huis te bly - dat N.P. van Wyk Louw'n affiniteit vir die werk van Hendrik Marsman gehad het en dat laasgenoemde se werk invloed op Louw uitgeoefen het. Dit is egter'n studie op sigself en raak die onderhawige onderwerp slegs sydelings. 


\section{Funksie en invloed in die Nederlandse letterkunde}

4.1 My praktiese toeligting oor die verhouding tussen literatuur en gemeenskap, veral wat betref die funksie en invloed, is gebaseer op voorbeelde uit die Nederlandse letterkunde by name die poësie uit die Middeleeue, die Renaissance, die Romantick van die negentiende eeu en die kuns van die moderne tyd. 'n Mens moet geredelik toegee dat die keuse van voorbeelde soms subjektief kan wees en dat die ideaal van die hoogste objektiwiteit in hierdie opsig onbereikbaar is.

\subsection{Die Middeleeue}

In hierdie opwindende tydperk - ook wat die literat uur betref - bestaan daar wat die gemeenskap betref' 'n skerp indeling van adellikes, geestelikes en burgerlikes. Literatuurhistorici het op grond van hierdie indeling ook al onderskeidings gemaak in die kuns van die Middeleeue. 'n Belangrike faktor wat by die beskouing oor die funksie van die literatuur in ag geneem moet word, is die feit dat die meerderheid van die Middeleeuers, ook die adellikes analfabete was. Lees en skryf is op een tydstip die monopolie van die geestelikheid. Om te leer lees en skryf in die Middeleeue het min of meer beteken dat so 'n persoon geestelike sou word (kyk Demyttenaere e.a.: 15). Die bepaalde gesteldheid van die gemeenskap van die Middeleeue het ingehou dat die geskrewe werk gehoor moes word: "... het publiek van het boek is het auditorium! Het lezen van een boek (was) een audiovisueel gebeuren..." (op. cit., p. 16). Laasgenoemde het meegebring dat die dramatiese en die drama in hierdie tydperk opgang gemaak het. Die gesproke en vertolkte woord het die hoofaandag gekry. Daarvan getuig ook die talle soorte dramas, die misteriespele, die mirakelspele, die abelespele, die sinnespele en die sotternieè, klugte, sproke, ensovoorts. Ook die ridderromans en die volksballades het 'n dramatiese (praat)inslag gehad. 'n Mens hoef alleen maar te luister na die aanhef van die bekende ridderroman karel ende Elegast waarin die voordragkunstenaar hom dadelik manifesteer:

Vraye historie ende al waer

Maghic u tellen, hoerter naer.

'n Mens kan dus konstateer dat die aard van die gemeenskap in die Middeleeue 'n sekere invloed op die vorm van die kuns had: die kuns moes in 'n belangrike mate praatkuns wees. Die gevolgtrekking sluit natuurlik nie die bestaan van die indiwidualistiese liries-ontboesemende kuns in die Middeleeue uit nic. Wie ken nie die "skoonste dorleklag" (á la Coster) van die Nederlandse letterkunde nie?"

Egidius waer bestu bleven

Mi lanct na di gheselle mijn

Du coors di doot du liets mi tleven.

Baie Middeleeuse werke het die funksie gehad on vertolkers van Bybelse waarhede te wees. Jan van Boendale met sy "Hoe dichters dichten sullen...", die eerste Dietse ars poetica, het waarlıeid en waaragtigheid in die kuns vooropgestel en daarvan uit gegaan dat

... Jhesum Christum

Die allene is die waarhede... (vs. 217). 


\subsection{Die Renaissance}

Waar die digkuns van die Middeleeue in 'n groot mate bedocl was vir die volk, veral tot lering, is die literatuurvan die Renaissance minder volksgerig en eksklusiewer as dié van die Middeleeue. Dic kuns het ' $n$ ander rol in die gemeenskap begin speel. Dit geld ook vir die literêre kunstenaar: "Niet langer is hij vooral leverancier van een zeker soort gebruiksgoederen voor de gemcenschap. Hij is nu iemand geworden die in dichtvorm zichzelf uitlevert en dit niet laten kan" (Van der Heijden, 1967:7). Vondel, Hooft, Bredero en Luyken, om maar 'n paar belangrike Renaissansiste te noem, het hulle elkeen op hul eie manier in hulle kuns "uitgelewer". Soos Knuvelder (1971:32) dit stel, het die "religieuze eenheid van wereld en levensbcschouwing ten einde" geloop. 'n Faktor wat hier 'n rol gespecl het, was die Hervorming van 1517, wat die mens in 'n sekere sin losgemaak het van die knellende bande van die kerk as instituut. Die verandering van ingesteldheid van kuns, kunstenaar en gemeenskap het gepaard gegaan met die verabsolutering van die vorm. 'n Mens dink veral hier aan die vermaarde sonnet, die aleksandryn, die strak rymskemas, kortom die "hechte en strakke vormen van orde en regelmaat" (Knuvelder).

'n Besondere eksponent van die Nederlandse Renaissance was die digter P.C. Hooft wat beskou kan word as die middelpunt van die beskaafde lewe van sy tyd en sy land. Van der Heijden (1967:7) meen dat die Renaissance in hom voltooi is. Oor die aard en funksie van die literatuur, by name die poësie, het Hooft 'n uiteenset ting gegee in sy beroemde "Reden vande Waerdicheit der Poësie". Hy prys die poësie hoog aan; "Dese is niet alleen heel suiver, heel gesondt, heel gerust, soo datter niemanden hart, hooft oft tand afsweere: maer doet meer". Die poësie laat 'n naklank in die gemoed, 'n nakklank van 'n lieflike sang tot heilsame stigting wat weer kan lei tot "stichtelijke en nutte daeden. Poësie sc invloed strek wyd, aldus Hooft, en is selfs in staat tot wapenfeite en het in die hoedanigheid al dienste bewus "in ' $t$ verstooten vande Tyrannje en stichten des vrijheids..." (op. cit.:58).

Huizinga (1963:1 10) wys daarop dat die kuns, die literêre kuns altans van die Goue Eeu, die plek ingeneem het wat die preek oopgelaat het. By die ontbreking van 'n stroom daaglikse nuus en nuwe lektuur was daar tyd en aandag vir die letterkunde as sosiale funksie: " $\mathrm{Zij}$ vormde het hoofdornament van het geestelijke bestaan, een edel vermaak; zij was in hoge mate verbonden aan al wat feest of plechtigheid was. Hoeveel van de litteratuur ontstond niet als huldiging, viering, inwijding of herdenking, als lofdicht, opdracht, huwelijkszang, grafdicht?" (op. cit.:111).

Namate die era van die Goue Eeu verbygegaan het, het nuwe tye aangebreek. Die eksklusiwiteit van die poësie het ietwat verlore gegaan. Die literatuur het in gemoedeliker vaarwaters beland en was 'n tydlank ởie speelbal van die Romantiek totdat 'n laagtepunt bereik is in die eerste helfte van die vorige eeu met die opkons van die Nederlandse predikantdigters.

Soort vaderfiguur vir die gemoedeliker literatuur was Vader Cats (1577-1660), tydgenoot van Hooft en Vondel. 


\subsection{Die Romantiek en die Tagtigers}

Tesame met allerlei historiese ontwikkelinge in die Nederlande, die agteruitgang van staat en ekonomie het ook die kuns na die Goue Eeeu - soos die Nederlanders dit stel - verloeder. Die literèr-historiese ontwikkelinge word met sewemylslaarse in oënskou geneem, maar wat die sprong van die Goue Eeu na die tydperk van die Tagtigers hetref, verkeer ek in goeie geselskap. Lodewijk van Deyssel het byvoorbeeld in ' $n$ lofprysende artikel oor Willem Kloos 'n soortgelyke sprong gemaak en gesé dat hy na die "spheer van Vondel... overging in de spheer van Willem Kloos" (1943:195). Die toestand van die bevoogding van die kuns deur die gemeenskap kulmineer in ' $n$ figuur soos Bilderdijk (1756-1831), wat byvoorbeeld as digter die kombuis betree het en in geswolle retoriek oor die kook van 'n eier skryf.

J.J.L. ten Cate skryf in 'n juigtoon oor sy seun se eerste tand:

Triomf, triomf! hef aan, mijn luit, Want moeder zegt: de tand is uit!

Laat dreunen nu de wanden!

Eerst gat Gods goedheid het lieve wicht

den adem en het levenslicht;

Nu geeft zij 't wichtje tanden.

'n Mens kan allermins beweer dat digters soos Bilderdijk, De Genestet en ander tydgenote glad nie verdienstelike werk gelewer het nie en dat geen belangrike digters tussen Vondel en Kloos hulle verskyning gemaak het nie. Tog was die toestand oor die algemeen - literêr gesien - bedroewend. Van Deyssel laat hom minder vleiend uit oor die stand van kuns en kunstenaar van sy tyd wat die gemeenskap na wil en welbehae begin bedien het: Hy skel die beoefenaars van die kuns in die negentiende eeu uit vir "vijftigjarige zuigelingen" (1943:78); 'n "kudde buftels van de middelmatigheid" (op. cit.:79); "lappendekens, opgevuld met den wezenloze wind van uw 'gevoel van eigenwaarde' " (79); "kleinen van ziel en kleinen van taal"; "hoogeschool-potentaten" (80). Hy beskuldig hulle daarvan dat hulle die literatuur tot "een riool van vunzige banaliteit" (78) verlaag het. Hiermee beswadder hy dus 'n tydperk in die literêre kuns - en nie ten onregte nie - waarin die letterkunde, veral die poèsie, 'n laagtepunt bereik het en geen enkele verheffende funksie of invloed gehad het nie as om huislik te stręel en te verneder. Nie dat die huislike geen onderwerp van groot poësie kan wees nie. Soos Ten Cate en ander dit egter aangewend het, was verregaande. Wat verwag Van Deyssel dan wel van die kuns?

By hom gaan dit in die kuns om die "groote, diepe heftige aandoeningen" (78); "het groote menschengevoel"; die mens se "ongekende diepten" (81); die "groote oneindigheid door vorige volken verpersoonlijkt en aanbeden" (82); "Het hooge woord van groote schoonheid..." (83).

Die antwoord op Van Deyssel is die Beweging van 'Tagtig met Willem Kloos as vernaamste verteenwoordiger. Opnuut word die kuns minder gemeenskapsgerig en meer vormgebonde. 
Die digter van "Ik ween om blocmen in re knop gebroken" en "Ik ben een God in 't diepst van mijn gedachten" het die literêre kuns allermins as gemeengoed beskou. Die Icrende en die didaktiese kuns van sy voorgangers het plek gemaak vir die kuns van dic sielsuit beelding: "de allerindividueelste expressie van de allerindividucelste gevoelens..." In sy beroemde inleiding tot Jacques Perk noem hy die poësie "Eene gave van weinigen voor weinigen..." (Van der Heijden, 1972:112). Ek wil 'n oomblik stilstaan by Kloos se merkwaardige tydgenoot Herman Gorter (1864-1927), die . digter van Mei. Met laasgenoemde gedig - so het hy self gesê - wou Gorter iets ligs. en sonnigs skep, maar die van u wat Gorter se lewensgeskiedenis ken, weet dat hy hom tot die sosialisme gewend het, bevriend geraak het met Lenin en die vergadering van die Derde Internasionale in 1920 in Moskou toegespreek het. Vir Gorter het die poësie die funksic verwerf om diensmiddel vir die mensheid te wees soos wat dit ook in die Marxistiese literatuurbeskouing die geval is. In hierdie opsig bicd die reeks gedigte onder die titel "De Arbeidersraad" interessante voorbeelde waarvan die volgende een is:

Nu dan de nederlaag geleden is,

In der tirannic donkre duisternis,

Nu wil ik zingen, zacht en hel en fijn,

Dit wil ik zingen in een gouden schijn.

In nederlaag wil ik hun dichter zijn.

In die verbygaan verwys ek na Henriëtte Roland Holst van der Schalk (1869-1952) wat as geesgenoot van Gorter die poësic en drama ook in diens van die mensheid wou stel en gestel het.

\subsection{Die moderne tyd}

Vir die docleindes van hierdie geskrif verwys ek, wat die moderne tyd betref, na dic Nederlandse poësie van die Vyftigerjare wat as modern beskou word vanweè die sterk anti-tradisionalistiese ingesteldheid. Uit die voorgaande sou 'n mens al kon aflei dat veranderings in kunsopvattings, beskouings oor die literatuur, dikwels gepaard gaan met en die gevolg is van nuwe mensbeskouings, geinspireer deur lilosofiese st romings en ingrypende gebeurtenisse. Dit is byvoorbeeld die geval met die Nederlandse poësie na 1945 wat beinvloed is deur die bepaalde mensbeskouing wat ontstaan het na die geweldige menseslagt ings van dic afgelope wêreldoorloè. Die geloof aan dic estetiese, die mooie en die verheffende is ernstig geknou. Remco Campert skryf:

Nu Roland Holst oud geworden is

en vierregelrijmen wisselt met Vestdijk

...

wordt het tijd dat wij iets laten horen een stem die dwars door puinstof heen, die glipt door de spijkers van het bedskelet die nooit de baard in de keel wil hebben 
Jie aanvoerder van die Nederlandse Vyftigers, Lucebert, het in sy gedig "Het orakel van Monte Carlo" verdoemend afgereken met die Tagtigerverheerliking van die skoonheid. Die estetisisme van Willem Kloos en sy tydgenote beskou hy as afgedaan en in die genoemde gedig laat hy voos heel gepas rym op Kloos. Dit is in der waarheid so dat die gemeenskap en ontwikkelinge in die gemeenskap 'n rol gespeel het in die ombuiging van die koers wat die Nederlandse poèsie sedert Tagtig ingeslaan het. Meer nog: 'n internasionale gemeenskap (in die kleine), het hieraan meegewerk. Ek wil hier veral ook wys op die dadaïsme wat beinvloedend gewerk het. Te midde van die geweld van die Eerste Wêreldoorlog het mense soos Hans Arp meegehelp aan die ontwikkeling van die dadaïsme. Simon Vinkenoog noem die dada ïsme die profesie van die niks. Wat die kuns - ook die literatuur - betref, wou die dadaiste by 'n nulpunt begin. Dada het hom verset teen alles waarteen jy jou kan verset: teen God, die maatskappy, die rede en alle bestaande etiese en artistieke norme (Schippers: 1974). Die vaste benaminge van dinge en die betrekenisse van woorde is deur die dada ïste ernstig bevraagteken. Francis Picabia (Ades: 31 ) se dadaïstiese manifes lui so:

Het is als jullie hoop en verwachtingen: niets.

als jullie paradijs: niets

als jullie idolen: niets

als jullie politici: niets

als jullie helden: niets

als jullie kunstenaars: niets

als jullie religie: niets.

Dit het sy uitwerking gehad op die aard, funksie en invloed van die kuns, by name die poësie. Die dadaisme het sy doel bereik met die verbrokkeling van die vaste vortme. In die poèsie is die versrećl losgemaak van die swaartekrag van die sinsverband, die grammatika se bande is opgehef en tipografiese plasing moes vry wees.

Die uit werking en die invloed van die dadaïstiese tendense - en ek wil surrealistiese en futuristiese invloede nie uitskakel nie - was dat ernstig aandag bestee is aan die aard van die poësie en dat baie gedigte gewy is aan die maakwerk, die skeppende werk. By Lucebert, Lco Vroman en Kouwenaar kry 'n mens as uitvloeisel hiervan ' baie besinnings oor die skepping van die gedig. Die skeppende arbeid is by hulle dikwels belangriker as die resultaat van die skeppingswerk.

Waar die Tagtigerpoèsie esteties-strelend was, is die poësie van die Vyftigers dit minder en eerder skokkend vanweë sy anti-t radisionele aard. Lucebert, Kouwenaar en ander won werklikheidsdigters wees: "Droom is het leven niet..." het Kouwenaar iewers gesê en daarmee geimpliseer dat hy juis lewe en werklikheid in die poësie wou uitbeeld. Tog is hulle nie digters van en vir die gemeenskap nie; net so min sous wat Breyten Breytenbach so 'n digter is. Soos die 'I aytigers se kuns is die van die Vyftigers ook elitêr en dikwels hermeties.

\section{Slotsom}

Om ten slotte 'n paar drade saanı te vat: Die vraag na die aard en funksie van die 
litcratuur het mense al ceuclank besig gehou. Aristoteles het in sy Poëtika oor die aard van die kuns besin en Plato het al gevra na dic funksic daarvan. Saam met Wellek en Warren (1971:55) kan 'n mens egter sê dat dit nie 'n vraag is wat onwillekeurig by digters en poësielesers opkom nie, want sê hulle: Die skoonheid reguerdig homself.

Uit bogaande het geblyk dat poësie deur die ecuc op verskillende maniere beskou en verskeie funksies daaraan toegedig is. Veral in die Middeleeue was die literatuur besonder gemeenskapsbetrokke en het die poësie 'n sterk religieuse funksie gehad.

In die Renaissance is die poësic onder andere gesien as 'n middel tot skoonheidsontroering, maar tegelykertyd het dit gedien tot lering en vermaak.

Tagtig het die literère kuns bedrywe, altans gedurende die ecrste klompie jare, ter wille van die kuns.

In die moderne tyd het die kuns, veral die poësie, weer meer hermeties geword, meer as ooit te vore. Dit beteken nie dat die poësie in die moderne tyd nie gemeenskapsgerig is nie. Inteendeel: die modernere poësie is geneig om meer as ooit aktueel te wees en sake van die dag, veral politieke sake, tot onderwerp te verklaar.

Dit is inderdaad so dat die poësie op verskillende tye vir verskillende soorte lesers verskillende funksies kan verrig. Die historikus, aldus Wellek en Warren (1974:47) kan dit as 'n sosiale dokument gebruik. Die psigoloog kan poog om iets van die menslike sielelewe daaruit te haal. Die poësie kan dien tot kennisoordrag.

Ernstige literatuurlesers en -kenners behoort dit egter daaroor eens te wees dat die literatuur iets unieks is en dat poësie byvoorbeeld nie in die eerste plek in diens van iets anders staan nie. Dit is allereers skepping van die lewensgevoelige kunstenaar wat die gedig kan gebruik vir die ontlading of uitstorting van sy gevoelens op sy eie en unieke wyse. Dit neem egter nie weg nie dat poessie, soos hierbo aangedui, sekere funksies kan verrig. Die eerste en belangrikste is egter dat, aldus Wellek en Warren, poësie getrou moet wees aan sy eie aard. En hier is ' $n$ mens in ' $n$ sekere sin weer terug by die ou beginsel van "l'art pour l'art" met die gedagte "dat werkelijk grote kunst, of goede kunst, of kortweg kunst, nooit propaganda kan zijn"' (Wellek \& Warren, 1974:53). Aan die ander kant kan kuns nie in 'n kokon bestaan nie. Agter elke kunstenaar en in elke kunswerk skuil 'n bepaalde lewensbeskouing. En hierdie lewensbeskouing is, aldus Wellek en Warren (op. cit.: 54), iets wat baie meer verfyn is.

Ten slotte invlord: Hieroor wil ek kort wees. Soos reeds hierbo meegedeel, kan een litcrêre werk 'n ander een beïnvloed soos een kunstenaar 'n ander een. 'n Gemcenskap of die samestelling van 'n gemeenskap kan weer die kuns en die vorm van die kuns beinvloed en ten slotte kan die literêre werk die gemeenskap beīnvloed, hoewel hierdie soort invloed nie oorskat moct word nie, veral vanweč die elitêre en hermeticse aard van dit wat vandag vir gocie kuns deurgaan. 


\section{BIBLIOGRAFIE}

ADES, D. 1976. Dada en surrealisme (vert. Peter Nijmeijer). Amsterdam, Landshoff.

ANBEEK, T. 1974. De literatuurwelenschapen de lezers. De Gids, 137e jg., nr. 3, p. 159-178.

DEMYTTENAERE, A. e.a. 1976. Literatuur en samenleving in de middelecuwen. Wassenaar, Servire.

GIELEN, J. e.a. 1974. Massaliteratuur - Een onderzoek naar de schriftroman Saskia. Nijmegen, Studiegroep (eie uitgawe).

GRAY, B. 1975. The phenomenon of literature. Den Haag, Parys, Mouton.

HALL, J. 1979. The sociology of literature. New York, Longman.

HERNADI, P. (red.) 1978. What is literature. Londen en Bloomington, Indiana University Press.

HUIZINGA, J. 1963. Nederland's beschaving in de 17de ecuw. Haarlem, Tjeenk Willink \& Zoon.

KNUVELDER, G. 1971. Handboek tot de geschiedenis der Nederlandse letterkunde (Deel 2). 's Hertogenbosch, Malmberg.

MAATJE, F.C. 1977. Literatuurwetenschap. Grondslagen van een theorie van het literaire werk. Utrecht, Bohn, Scheltema en Holkema.

ROSENHEIM, E.W. 1960. What happens in literature. Londen en Chicago. University of Chicago Press.

SCHOPENHAUER, A. 1980. Over schrijven en stijl (vert. H.J. Pott). De Revisor, 7de jg. nr. 4, Augustus, p. 25-30.

SEGERS, R.T. (red.). 1978. Receptie-esthetika - Grondslagen, theorie en toepassing. Amsterdam, Huisaandedriegrachten.

TUYNMAN, P. (red.) 1971. P.C. Hooft - Somnetten en Reden vande Waerdicheit der Poesie. Amsterdam, Athenaeum-Polak \& Van Gennep.

VAN DER HEIJDEN, M.C.A. 1967. De ziel van de poëet vertoont zich in zijn dichten. Lyriek van vier Amsterdanse dichters uit de $17 \mathrm{e}$ eeuw.

VAN DER HEIJDEN, M.C.A. 1972. Een nieuw geluid. De Tachtigers in proza en poëzie.

VAN DEYSSEL, L. 1943. Proza (versorg deur H.A. Mulder). Pretoria, J.L. van Schaik.

SCHIPPERS, K. 1974. Holland Dada. Amsterdam, Querido.

WELLEK, R. \& WARREN, A. 1974. Theorie der literatuur (vert. Tom Etty e.a.). Amsterdam, Athenaeum-Polak \& Van Gennep. 